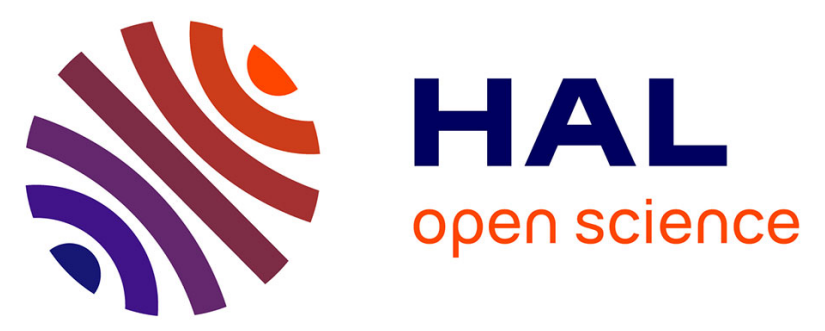

\title{
Food matrix structure (from Biscuit to Custard) has an impact on folate bioavailability in healthy volunteers
}

Caroline Buffière, Manon Hiolle, Marie-Agnès Peyron, Ruddy Richard, Nathalie Meunier, Cindy Batisse, Didier Remond, Didier Dupont, Francoise Nau, Bruno Pereira, et al.

\section{To cite this version:}

Caroline Buffière, Manon Hiolle, Marie-Agnès Peyron, Ruddy Richard, Nathalie Meunier, et al.. Food matrix structure (from Biscuit to Custard) has an impact on folate bioavailability in healthy volunteers. European Journal of Nutrition, 2021, 60, pp.411-423. 10.1007/s00394-020-02258-5 . hal-02884815

\section{HAL Id: hal-02884815 https://hal.inrae.fr/hal-02884815}

Submitted on 30 Jun 2020

HAL is a multi-disciplinary open access archive for the deposit and dissemination of scientific research documents, whether they are published or not. The documents may come from teaching and research institutions in France or abroad, or from public or private research centers.
L'archive ouverte pluridisciplinaire HAL, est destinée au dépôt et à la diffusion de documents scientifiques de niveau recherche, publiés ou non, émanant des établissements d'enseignement et de recherche français ou étrangers, des laboratoires publics ou privés.

\section{(ㅇ)(1) $\$$}

Distributed under a Creative Commons Attribution - NonCommerciall 4.0 International 


\title{
Food matrix structure (from Biscuit to Custard) has an impact on folate bioavailability in healthy volunteers
}

\author{
Caroline Buffière $^{1} \cdot$ Manon Hiolle $^{2} \cdot$ Marie-Agnès Peyron $^{1} \cdot$ Ruddy Richard $^{3} \cdot$ Nathalie Meunier $^{3} \cdot$ Cindy Batisse $^{5,6}$. \\ Didier Rémond ${ }^{1} \cdot$ Didier Dupont $^{2} \cdot$ Françoise Nau $^{2} \cdot$ Bruno Pereira $^{4} \cdot$ Isabelle Savary-Auzeloux ${ }^{1}[$
}

Received: 4 November 2019 / Accepted: 22 April 2020

(c) Springer-Verlag GmbH Germany, part of Springer Nature 2020

\begin{abstract}
Purpose We examined the impact of matrix food structure on post-prandial folate bioavailability (and other macronutrients) in human volunteers using a randomized, controlled, crossover experimental design.

Methods Twelve healthy male volunteers $(22.6 \pm 0.4$ years old) were offered four food models (differing in matrix structure: Custard, Pudding, Sponge cake and Biscuit) to which $1 \mathrm{mg}$ of folic acid was added, according to a randomized, controlled, crossover experimental design. Plasma folates, glucose, insulin, alpha amino nitrogen and triglycerides were measured over the post-prandial period (from $\mathrm{T} 0$ to $\mathrm{T} 480 \mathrm{~min}$ ).

Results Food matrix structure was capable of altering folate plasma availability. The highest folate availability was observed for pudding and to a lesser extent Sponge cake whereas the lowest was for the two matrices presenting extreme rheological properties: Custard (liquid) $(P<0.05$ total AUC) and to a lesser extent Biscuit (hard solid) $(P<0.05$, AUC 180 min). The analysis of plasma kinetics of appearance of other nutrients/metabolites helps to understand/explain the lower bioavailability of folates in Custard and Biscuit.

Conclusion A least overall efficient bio-accessibility of all macronutrients and folic acid is observed in the gut lumen for Biscuit (delayed/incomplete destructuration of biscuit along the digestive tract). On the contrary, the lower folic acid absorption observed with custard does not fit with the rapid plasma appearance of other nutrients and should require further investigation.
\end{abstract}

Keywords Food structure $\cdot$ Folate $\cdot$ Folic acid $\cdot$ Clinical trial $\cdot$ Bioavailability

Caroline Buffière and Manon Hiolle contributed equally to the work.

Isabelle Savary-Auzeloux

isabelle.savary-auzeloux@inra.fr

1 University Clermont Auvergne, INRAE, Unité de Nutrition Humaine, UMR1019, 63000 Clermont-Ferrand, France

2 Science et Technologie du Lait et de l'Oeuf, INRAE, AGROCAMPUS OUEST, 35042 Rennes, France

3 CHU Clermont-Ferrand, Centre De Recherche En Nutrition Humaine Auvergne, 58 rue Montalembert, 63000 Clermont-Ferrand, France

4 Biostatistics Unit (DRCI), University Clermont Auvergne Hospital Clermont-Ferrand, 58 rue Montalembert, 63000 Clermont-Ferrand, France

5 Dental Faculty, University Clermont Auvergne, CROC EA4847, 63000 Clermont-Ferrand, France

6 Dental service, CHU Clermont-Ferrand, 63000 Clermont-Ferrand, France

\section{Introduction}

Folates are a group of heterocyclic compounds based on the pteroic acid skeleton conjugated with one or more L-glutamate units. They are involved in the regulation of various metabolic pathways within the cells such as nucleic acid synthesis and one carbon metabolism (for instance, regeneration of methionine from homocysteine) [1]. Any alteration of these folate-requiring metabolic pathways can impact greatly on cell division and homeostasis, and folate deficiency has been associated with an increased risk to develop megaloblastic anaemia, chronic diseases (vascular diseases), reproductive disorders [impact on incidence of neural tube defects (NTD)] and alteration of cognitive function in the elderly [1-3].

Even if $1000 \mu \mathrm{g} /$ day is generally considered to be the maximum daily folate intake for adults (to avoid any adverse effect), the maximum recommended daily intake (RDI) is settled at $330 \mu \mathrm{g} / \mathrm{day}$ for adults and $600 \mu \mathrm{g} / \mathrm{day}$ for pregnant 
women by European Food Safety Authority [4]. These recommendations should cover folate requirements via an adequate nutritional supply [1]. As it has been shown that plasma or blood folate concentrations were increased after folic acid supplementation on a short term [5, 6] and a long-term basis [7], food fortification in folic acid in grain products has been mandated by the US Food and Drug Administration since 1998; this is not the case in several European countries. This policy has been intended to target a specific population: women in the age of becoming pregnant [2] to limit the occurrence of NTD in the population. Several studies have shown that these food fortifications in folic acid have reduced the prevalence of NTD in these populations [2, 8-10]. However, potential adverse effects of food fortification in folic acid on the overall population's health have also been mentioned [10-12]. One of the most documented adverse effects of food fortification in folic acid is the aggravation and/or masking of vitamin B12 deficiency, particularly in elderly population or even during pregnancy. Then vitamin B12 deficiency is directly responsible for an increased occurrence of various age-related diseases: megaloblastic macrocytic anaemia, cardiovascular diseases, neurological pathologies, and osteoporosis $[10,11,13]$. In parallel, the impact of folic acid supplementation on cancers (colorectal cancers in particular) remains a matter of debate [14]. To summarize, although food fortification in folic acid has been shown to decrease the occurrence of NTD, some side deleterious effects (particularly towards elderly population) are still questioned in the literature. The optimal dose of folic acid supply (ranging from 0.4 to $40 \mathrm{mg}$ per day used in interventional studies [14]) on the short-term and the long-term basis $[11,15]$ capable to improve overall health status also remains a matter of debate.

In this context, the actual assessment of folate bioavailability (i.e., fraction of folates ingested that are absorbed and become available to the body for utilization or storage in healthy individuals) or bioefficacy (as described by Brouwer et al. [16]) is essential [16]. Indeed, the quantity and form of folate supplies should be adapted to fit better with population requirements, according to their age or health status. Plasma folate concentration in the fasted and fed state is considered to be an indicator of folate bioavailability [6]. However, the plasma folate levels (more precisely plasma 5-methyltetrahydrofolic acid level) are the consequence of the metabolic use of folates within the body. Plasma/blood folate concentrations are the result of folate appearance and disappearance within the plasma compartment [16]. Indeed, folate bioavailability is the result of various interacting parameters: (1) the chemical structure of folates supplied (mono- or polyglutamyl chains), (2) the vector (food) used for folate supply, (3) the digestion process of food containing folates (starting in the mouth) and (4) the efficiency of folate absorption by the intestinal brush border/activity of the carrier-mediated absorption of folates [17]. Among all these parameters, one factor has been rarely studied but mentioned to impact on folate absorption: the matrix effect that involves the interaction of folates with food components and/or entrapment within the food matrix [18]. Generally, when the food matrix effect is studied, a comparison between synthetic folic acid (supplemented alone or added to grain products) and natural folates (present within variable food matrices rich in folates) is made. However, in such situations, folates supplied are also chemically different, which is also a parameter known to impact the bioavailability [6].

Consequently, the present work was designed to assess whether food matrix alone could significantly modify one specific form of folate (i.e., folic acid) bioavailability. Four different folic acid-enriched model foods (Biscuit, Sponge cake, Pudding and Custard) have been designed and the 5-methyltetrahydrofolic acid (MTFA) appearance in plasma of healthy volunteers was measured post-prandially (until $8 \mathrm{~h}$ post-food ingestion) according to a randomized controlled cross-over design. To make sure that the folate bioavailability was conditioned only by the matrix effect, the four matrices were designed so that macronutrient composition (proteins, lipids and carbohydrates) was similar between each food model. The only difference between the four model foods was their water content and their production process, which allowed the development of different micro- and macrostructures. Folic acid content in each food model was measured before ingestion.

\section{Methods}

\section{Subjects}

The ethical committee (IDRCB 2017-A01996-47) approved the study, and all subjects gave written informed consent after explanation of the purpose, the methodology and the potential risks. The Clinical Trial identification number is NCT03413267 (Clinical Trials.gov). Eleven healthy (BMI $22.1 \pm 0.4 \mathrm{~kg} / \mathrm{m}^{2}$ ) young men (22.6 \pm 0.4 years old) participated in the study. They all presented normal blood biochemical and haematological profiles (complete blood count (CBC), platelets, C-reactive protein (CRP), glucose, creatinine, urea, sodium, potassium, calcium, phosphorus and vitamin D) and a complete and healthy dentition (no pain, no masticatory disorders, normal maxilla-mandibular relationships, no dental treatment, and no orthodontic treatment since 3 years) that could affect masticatory effectiveness. Volunteers did not take any nutritional supplement or any medicine. 


\section{Preparation of food matrices}

One liquid (Custard) and three solid (Pudding, Sponge cake and Biscuit) micronutrient-enriched foods were designed. Custard was provided as a packed powder that was rehydrated and heated before use. Solid foods were produced no more than 2 months prior to use; they were stored at $-20^{\circ} \mathrm{C}$ as daily portions.

Each portion of food ingested by the volunteers contained $10 \mathrm{~g}$ wheat flour, $10 \mathrm{~g}$ pea flour, $10 \mathrm{~g}$ egg white powder, $31 \mathrm{~g}$ egg yolk powder, $54 \mathrm{~g}$ sugar and $20 \mathrm{~g}$ sunflower oil. Their water content varied as follows: $17 \mathrm{~g}$ for Biscuit, $119 \mathrm{~g}$ for Sponge cake, $170 \mathrm{~g}$ for Pudding and $376 \mathrm{~g}$ for Custard. Production flowcharts of the food matrices are presented in Fig. 1. All preparation steps were carried out with a kitchen robot Thermomix ${ }^{\circledR}$ TM5 (Vorwerk, Wuppertal, Germany). The cooking of solid foods was operated with a semi-professional convection oven (De Dietrich, Niederbronn-Les-Bains, France).
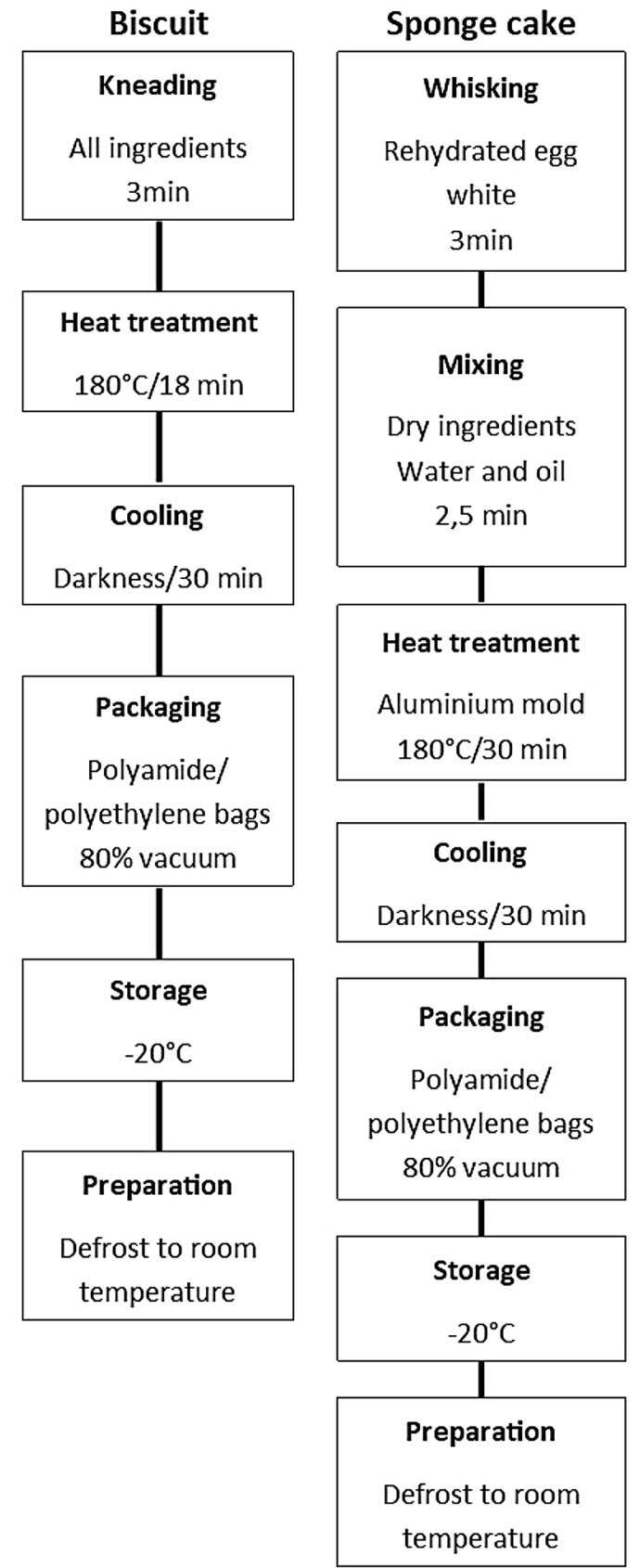

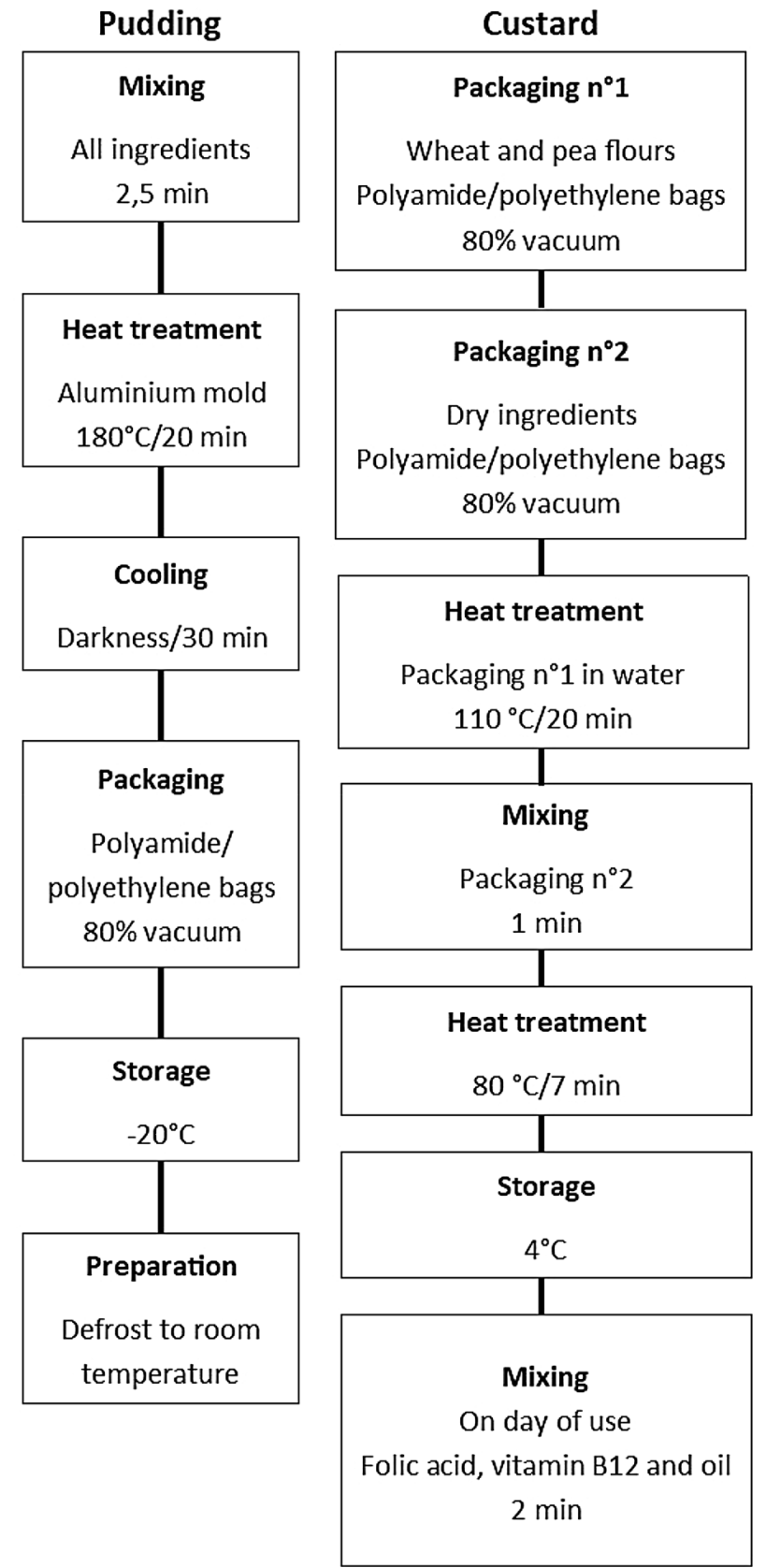

Fig. 1 Production flowchart of the micronutrient-enriched matrices 
On dry matter, the four matrices were all composed of $17 \%$ proteins, $52 \%$ carbohydrates and $30 \%$ lipids. The lipid content was gravimetrically determined after Folch's extraction; the protein content was determined by the Kjeldahl method. Before processing (for solid matrices) or on day of use (for Custard), each matrix was supplemented with $1000 \mu \mathrm{g}$ folic acid (Folic acid ref 05-050, Nutrilo $\mathrm{GmbH}$, Germany) and per portion ingested by the volunteers. All matrices were also supplemented with $12 \mu \mathrm{g}$ B12 vitamin (Folic acid, Vitamin B 12, ref 05-450, Nutrilo GmbH, Germany) and with fat-soluble vitamins so that the portion ingested by the volunteers contains lutein $(20 \mathrm{mg})$ and vitamin D (50 $000 \mathrm{UI})$. The present work will only focus on folate kinetic analyses. The analysis of lutein and vitamin D bioavailability will be detailed elsewhere (Reboul et al., submitted).

\section{Characterization of matrix microstructure}

Confocal laser scanning microscope observation of the four matrices was performed using the ZEISS LSM 880 inverted confocal microscope (Carl Zeiss AG, Oberkochen, Germany) set at the magnification $20 \times$ (Plan Apochromat objective, dry, NA 0.80). The protein network and fat components were stained using a $1 \%(w / v)$ Fast Green aqueous solution and a $0.1 \%$ (w/v) Nile Red 1,2-propanediol solution, respectively (Sigma Aldrich, St. Louis, USA). Both fluorescent solutions were first mixed at a ratio $1: 4$. Then $10 \mu \mathrm{L}$ of this mix was either deposited on the surface of the slice for solid matrices (Biscuit, Sponge cake and Pudding), or directly added to $100 \mu \mathrm{L}$ of the Custard, and vortexed. The samples were held at $20{ }^{\circ} \mathrm{C}$ for at least 10 min to permit the diffusion of the fluorescent dyes into the solid matrices. One drop of the labelled Custard was deposited on a glass slide. A cover slip sealed with an adhesive frame (Geneframe, ABgene House, UK) was then added on the top of the four different product slices, before observation using 488-633 nm excitation wavelengths in sequential beam fluorescent mode, for fat and protein detection, respectively, at a $1.32 \mu \mathrm{s}$ pixel dwell scanning rate. Red Nile and Fast Green were detected using a GaasP between 500 and $585 \mathrm{~nm}$ and a PMT between 635 and 735, respectively. Micrographs had a resolution of $0.15 \mu \mathrm{m} /$ pixel and were recorded in the samples at a constant depth of 10-15 $\mu \mathrm{m}$ from the glass slide. Images shown in this paper correspond to superimpositions of images of the same area observed separately with the two markers, with proteins coded in green and fat in red. Aqueous phase and any gas bubbles in the slices may appear as black holes in the micrographs. There were at least two samples of each product, and for each sample, at least 16 micrographs were recorded. The micrographs presented in Fig. 3 are representative of the different product samples.

\section{Experimental design}

All subjects were offered the four matrices according to a randomized, controlled, cross-over experimental design. The four sampling days were separated by at least 3 weeks of a wash-out period. During the 2 days before each scheduled sampling day, the volunteers were advised to consume diets poor in folates. On the day of sampling, they were in a fasted state (overnight fast). A catheter was inserted into a dorsal vein of the hand for venous blood sampling. A blood sample was withdrawn in the fasted state and then the volunteers ate one of the four foods. They also drank $200 \mathrm{~mL}$ of water within the $15 \mathrm{~min}$ post-food ingestion, then $100 \mathrm{~mL}$ every $2 \mathrm{~h}$ (up to $500 \mathrm{~mL}$ total water at the end of kinetic). Blood sampling was then withdrawn within the $8 \mathrm{~h}$ post-food ingestion (post-prandial state) $(30,60$, $90,120,180,240,300,360,420$ and 480 min after matrix ingestion). Blood was collected in EDTA-containing dark tubes, immediately centrifuged at $1500 \mathrm{~g}$ for $10 \mathrm{~min}$ at $4{ }^{\circ} \mathrm{C}$. Supernatant were then subsampled and stored at $-80^{\circ} \mathrm{C}$ until analysis.

\section{Sample analysis}

Plasma concentrations in folates were determined before (i.e., in the fasted state) and up to $8 \mathrm{~h}$ post-food ingestion using a radioimmunological assay (Simultrac B 12/Folates SNB kit, MP Biomedicals, Eschwege, Germany) and a gamma counter (Kontron, Augsburg, Germany). Insulin plasma levels were determined using an Enzyme-Linked ImmunoSorbent Assay (ELISA) test (Insulin ELISA kit, Mercodia, Uppsala, Sweden). Glucose (glucose PAP CP, Horiba, Montpellier, France) and triglyceride (triglyceride CP, Horiba, Montpellier, France) concentrations were measured using an autoanalyser (Pentra 400, Horiba, Montpellier, France). Total plasma free aminoacids were estimated by analysis of circulating total alpha-amino nitrogen according to a spectrophotometric method as previously described [19]. When unspecified, reagents came from Sigma-Aldrich, Saint Quentin Fallavier, France.

To determine folate content in ingested foods, frozen foods were powdered under liquid nitrogen and dry matter was determined. Folate extraction was performed according to [20]. A quantity of food (100 $\mathrm{mg}$ of each cooked food model, containing 200-500 ng of folic acid) was homogenized in $30 \mathrm{~mL}$ phosphate buffer $75 \mathrm{mM}$ containing $52 \mathrm{mM}$ ascorbic acid and $0.1 \%$ mercaptoethanol. After filling tubes with nitrogen to avoid oxidation, samples stayed $10 \mathrm{~min}$ in a boiling bath before centrifugation $11000 \mathrm{~g}$ for $20 \mathrm{~min}$. The pellet was washed with buffer, supernatants were pooled, volume was adjusted to $50 \mathrm{~mL}$ and analysed by radioassay. 


\section{Calculations}

All data obtained from the volunteers were plasma concentrations and measured during $8 \mathrm{~h}$. Measurements of metabolites were not duplicated but they were done at each time point of the kinetic (11 points, every 30 min during the first $2 \mathrm{~h}$ after food model ingestion, then every hour up to $8 \mathrm{~h}$ post-food model ingestion). The area under the curves (AUC) was calculated according to the trapezoidal method. Each individual basal concentration was used as baseline for the calculation of individual AUC. AUC was calculated over the $8 \mathrm{~h}$ following the food model ingestion but also within the first hours following food ingestion for specific plasma metabolites: $180 \mathrm{~min}$ for folates (to cover the period where folates range from basal level to maximal post-prandial value), $120 \mathrm{~min}$ for insulin (to focus on the transient post-prandial peak), and $240 \mathrm{~min}$ for alpha amino nitrogen (as the plasma concentration values return to baseline at this time point). For plasma folates, AUC results were expressed corrected or not by total ingested folic acid quantity. Peak plasma value (Cmax) and time when Cmax occurs (Tmax) were also determined.

\section{Statistical analysis}

Statistical analyses were performed using Stata software (version 13, StataCorp, College Station, US). All tests were two sided, with a type I error set at 0.05 . Continuous data were expressed as mean \pm standard error of mean. The assumption of normality was assessed using the Shapiro-Wilk test. Random-effects models for repeated data were performed to compare four ingested matrix: (1) considering the following fixed effects: matrix and for longitudinal analyses, time-point evaluation and time $\times$ matrix interaction, and (2) taking into account between and within participant variability (subject as random effect). Furthermore, due to cross-over randomized design, period, matrix order and carry-over were also considered as covariates. When appropriate, a Sidak's type I error correction was applied to perform multiple comparisons. The normality of residuals from these models was studied using the Shapiro-Wilk test. When appropriate, a logarithmic transformation was proposed to achieve the normality of dependent outcome.

\section{Results}

\section{Volunteers and food matrices}

The differences in processing conditions (Fig. 1) and water content resulted in four food matrices with very different macroscopic aspects: a hard solid Biscuit, an airy and dry Sponge cake, a humid and compact Pudding and a thick liquid Custard (Fig. 2). A continuous protein phase can be observed in confocal microscopy images of Biscuit, Sponge cake and Pudding, whereas small protein particles of about $50 \mu \mathrm{m}$ in diameter are seen in those of Custard, suggesting an aggregation of proteins in this matrix (Fig. 3). The disruptions of protein phase observed in the four matrices may be attributed to air bubble, non-homogenous mixing, or water phase. Regarding the lipid phase, Custard and Biscuit present bigger lipid droplets than the two other matrices, in which lipids are more diffuse. However, the shape of lipid droplets is different in Biscuit, in which large flakes of fat are observed, and in Custard, in which lipids are very globular. As a conclusion, the four designed foods strongly differ in both microstructure and macrostructure despite an identical macronutrient composition on dry basis.

As expected because of the level of folic acid supplementation (cf Sect. 2.2), the folate content measured in all matrices ingested by volunteers averages $1 \mathrm{mg}$. No significant differences were observed in overall folates supplied by the different matrices to the volunteers (Table 1). However, the numerical difference in the average of folate content exists and can have an impact on the estimation of folate availability assessment and, in particular, when AUC is calculated. Consequently, AUC for folate availability at different time points was calculated before and after correction for folate ingested, assuming that absorption of folates was linear within the range from 889 (Sponge cake) to 1096 (Pudding and Custard) $\mu \mathrm{g}$ of folates supplied.
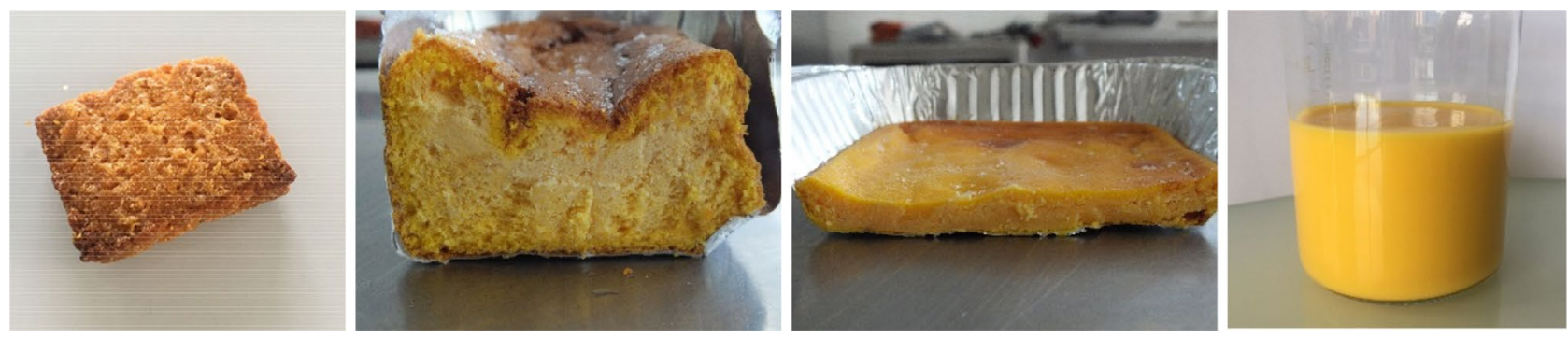

Fig. 2 Macroscopic images of the four matrices: Biscuit, Sponge cake, Pudding and Custard (from left to right) 

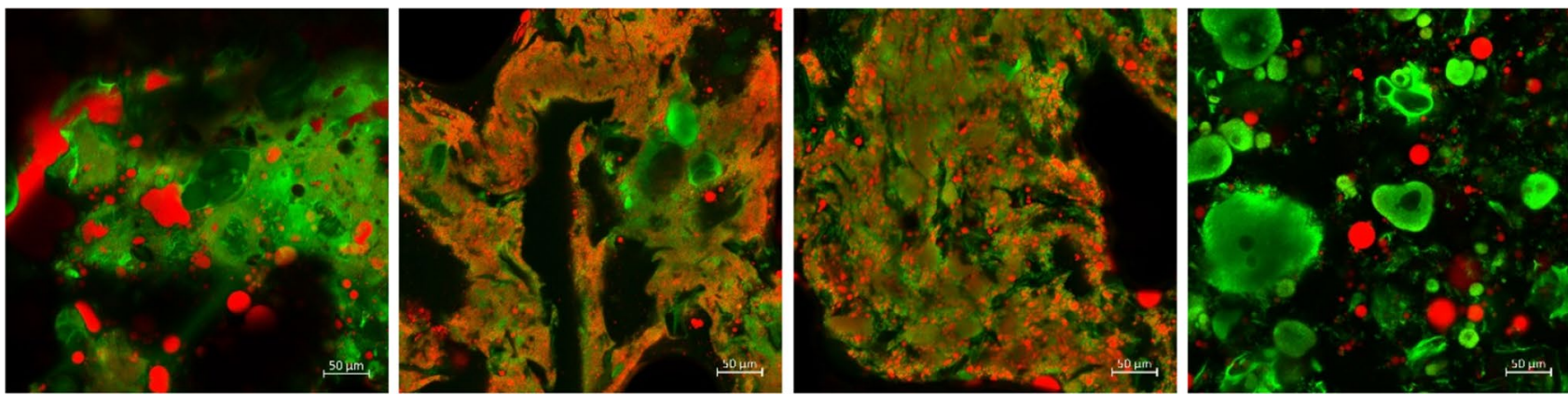

Fig. 3 Confocal images of the Biscuit (a), Sponge cake (b), Pudding (c), and Custard (d) at magnification $\times 20$ (lipids appear in red and proteins in green)

Table 1 Folic acid content measured in a portion of ingested matrices $(\mu \mathrm{g})$ and area under the curve (AUC, $\mathrm{ng} / \mathrm{mL}$.min) for plasma folate concentrations over the post prandial period

\begin{tabular}{lcllll}
\hline \multicolumn{7}{l}{ Corrected for ingested folate } \\
\cline { 2 - 6 } & Folic acid in matrices & AUC 180 min & AUC 480 min & Maximum value & T max \\
\hline Biscuit & $967 \pm 39$ & $1839 \pm 16 \mathrm{a}$ & $4516 \pm 279 \mathrm{ab}$ & $19,8 \pm 1.3 \mathrm{a}$ & $220 \pm 1 \mathrm{a}$ \\
Sponge cake & $889 \pm 60$ & $2299 \pm 186 \mathrm{~b}$ & $4789 \pm 271 \mathrm{a}$ & $21.7 \pm 1.2 \mathrm{a}$ & $180 \pm 7 \mathrm{~b}$ \\
Pudding & $1096 \pm 35$ & $2354 \pm 165 \mathrm{~b}$ & $4969 \pm 227 \mathrm{a}$ & $25.7 \pm 1.5 \mathrm{~b}$ & $180 \pm 7 \mathrm{~b}$ \\
Custard & $1096 \pm 100$ & $1696 \pm 135 \mathrm{a}$ & $3964 \pm 294 \mathrm{~b}$ & $20.2 \pm 2.0 \mathrm{a}$ & $200 \pm 9 \mathrm{~b}$ \\
\hline
\end{tabular}

Plasma folate concentrations AUC (ng/mL.min) 180 and 480 min post-ingestion of one of the four tested matrices: Biscuit, Sponge cake, Pudding and Custard. AUC were corrected for ingested folates. For each matrix, average maximum values $(\mathrm{ng} / \mathrm{mL})$ and time $(\mathrm{min})$ when the maximum value was observed $(\mathrm{T} \max )$. Values are means \pm SEM. For statistical description, see "Materials and methods"

\section{Plasma folates}

Regardless the food, plasma folate concentrations strongly increased within the 180 min post-ingestion, by 5.9 times on average between $\mathrm{T} 0$ and $\mathrm{T} 180 \mathrm{~min}$ (Time effect $P<0.001)$, then the concentrations declined slowly and progressively. At T480 min, the values were still higher than those measured in the fasted state $(9.09 \mathrm{ng} / \mathrm{mL}$ at T480 vs. $3.55 \mathrm{ng} / \mathrm{mL}$ at T0) but were similar between foods. Plasma folates differentially increased post-prandially (significant Time $\mathrm{x}$ Matrix interaction) with the highest plasma folate concentration observed for Pudding which differs from other foods from T120 to T240 $(P<0.05)$ (Fig. 4). Sponge cake is intermediate with plasma folate concentrations different from both the group Biscuit/Custard and Pudding at T120 $(P<0.05)$. When AUC was calculated and corrected from folates ingested, results are similar except that Sponge cake AUC at T480 becomes significantly higher than Custard $(P<0.05)$ and similar to Pudding and Sponge cake (Fig. 4, insert). Looking at the AUC over the first $180 \mathrm{~min}$ of the post-prandial period (AUC at T180 min) after correction for ingested folates, a similar matrix effect was observed (Table 1) with an AUC 180 significantly $(+27 \%, P<0,05)$ higher for Pudding and Sponge cake compared to Custard and
Biscuit. Lastly, folate absorption, when supplied in the Biscuit, was delayed by 30 min with a Tmax significantly $(P<0.05)$ higher $(220 \mathrm{~min})$ compared to 180,180 and 200 min for Sponge cake, Pudding and Custard, respectively $(P<0.05$, Table 1$)$.

\section{Other metabolites, nutrients and hormones}

\section{Insulin}

As generally observed post-prandially, insulin plasma concentrations increased rapidly, within the first $30 \mathrm{~min}$ after food ingestion (Time effect $P<0.05$; for Biscuit, Sponge cake, Pudding and Custard). Interestingly, and although the four foods presented the same composition in macronutrients (see "Methods" section), insulin concentration was higher 30 min after Custard ingestion compared to the other three foods $(1.70 \mu \mathrm{g} / \mathrm{L}$ for Custard vs. 1.14, 1.00 and $1.11 \mu \mathrm{g} / \mathrm{L}$ for Biscuit, Sponge cake and Pudding, respectively, Matrix effect, $P<0.001$; Time $\times$ Matrix effect $P<0.001$ ) (Table 2, Fig. 5). This is confirmed by AUC calculation within the first $120 \mathrm{~min}$ and $480 \mathrm{~min}$ postfood ingestion with significantly higher values for Custard compared to the other three matrices $(P<0.05)$ (Table 2$)$. 


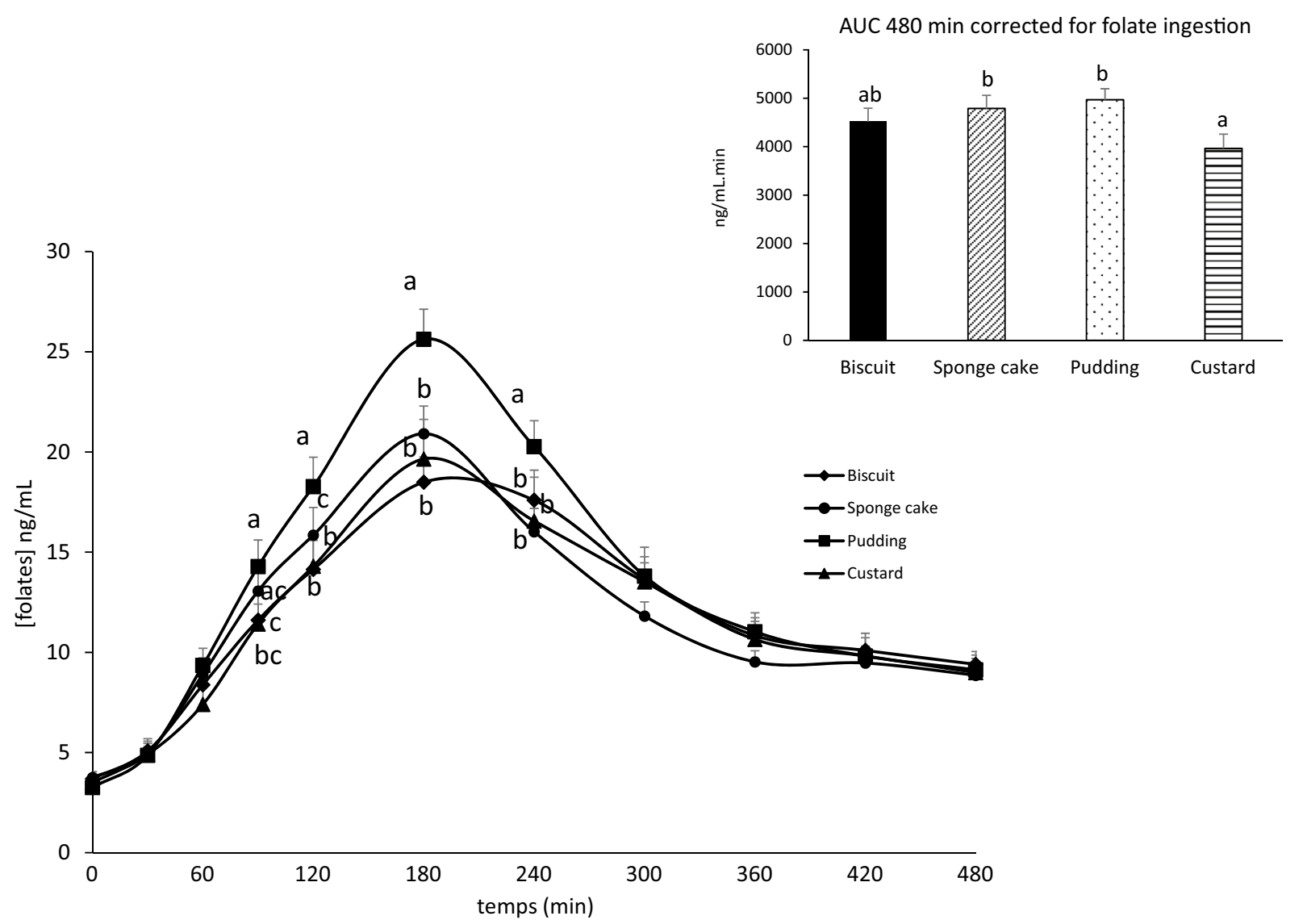

Fig. 4 Folate concentrations $(\mathrm{ng} / \mathrm{mL})$ in plasma over the post-prandial period and area under the curve (AUC, ng/mL.min) over the entire (480 $\mathrm{min}$ ) post-prandial period for the four tested matrices. Values are means \pm SEM. For statistical description, see "Methods"

Table 2 Plasma Insulin area under the curve (AUC, $\mu \mathrm{g} / \mathrm{L} . \mathrm{min})$ and maximum value over the post prandial period

\begin{tabular}{llrl}
\hline & AUC 120 min & AUC 480 min & Maximum value \\
\hline Biscuit & $66.2 \pm 11.5 \mathrm{a}$ & $79.9 \pm 19.7 \mathrm{a}$ & $1.14 \pm 0.18 \mathrm{a}$ \\
Sponge cake & $61,2 \pm 6.8 \mathrm{a}$ & $53.7 \pm 11.0 \mathrm{a}$ & $1.00 \pm 0.09 \mathrm{a}$ \\
Pudding & $70.8 \pm 9.9 \mathrm{a}$ & $85.4 \pm 13.3 \mathrm{a}$ & $1.11 \pm 0.15 \mathrm{a}$ \\
Custard & $92.6 \pm 9.8 \mathrm{~b}$ & $117.1 \pm 14.3 \mathrm{~b}$ & $1.70 \pm 0.24 \mathrm{~b}$ \\
\hline
\end{tabular}

Insulin concentrations AUC ( $\mu \mathrm{g} / \mathrm{L} . \mathrm{min}) 120$ and 480 min post-ingestion of one of the four tested matrices: Biscuit, Sponge cake, Pudding and Custard. For each matrix, average maximum values $(\mu \mathrm{g} / \mathrm{L})$. Values are means \pm SEM. For statistical description, see "Materials and methods"

\section{Glucose}

As for insulin, glucose plasma concentrations increased by $21 \%$ between the fasted state and T30 (Time effect $P<0.001$ ) (Fig. 6). This was followed by a rapid drop of glucose levels back to the fasted state values at T180 (Time effect no more significant). There is no matrix effect, nor significant Time $\times$ Matrix interaction.

\section{Alpha amino-nitrogen}

Total plasma amino-nitrogen (AAN) levels also increased post-prandially (Time effect $P<0.001$ ) for all matrices (Fig. 7). The higher post-prandial AAN content was observed later than for glucose and insulin (i.e., between 100 and $180 \mathrm{~min}$ ). Lastly, AAN concentration in plasma was lower for Biscuit than for Custard at T60 and T90 (Time x Matrix effect $P<0.05$ ) (Fig. 7). It should be noted that the Time $\times$ Matrix effect mentioned above is partially due to that the alpha amino nitrogen is not strictly the same in the fasted state depending on the foods (although not significantly different at T0). This explains why AUC, that integrates the basal level in its calculation, is no more significantly different between foods (Fig. 7, insert).

\section{Triglycerides}

Plasma triglyceride concentrations followed the same pattern of change as AAN after food matrix ingestion (Time effect, $P<0.001$ ) (Fig. 8). Custard ingestion resulted in a 


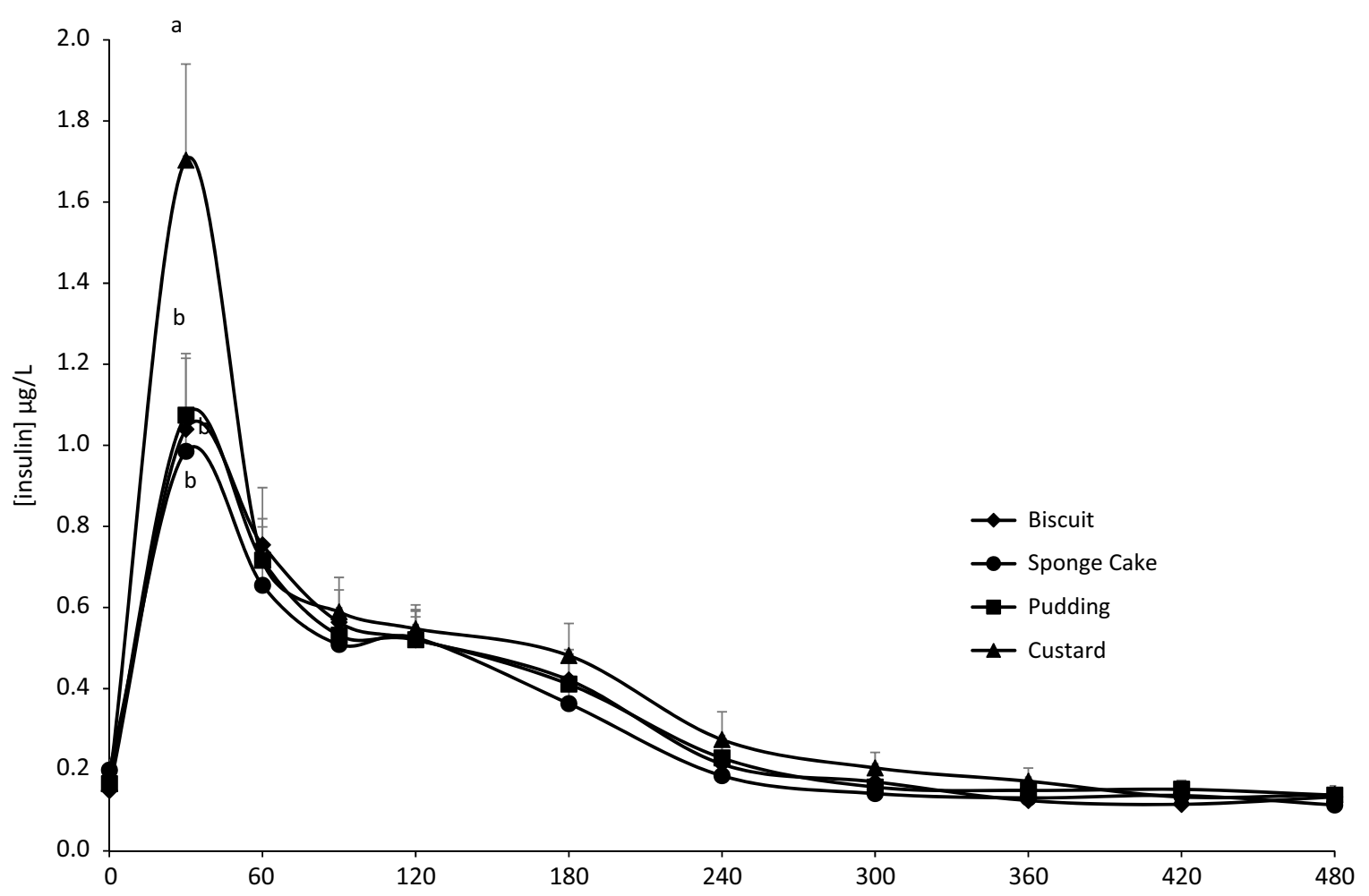

Fig. 5 Insulin concentrations $(\mu \mathrm{g} / \mathrm{L})$ in plasma over the post-prandial period. Values are means \pm SEM. For statistical description, see "Methods"

Fig. 6 Glucose concentrations $(\mathrm{mmol} / \mathrm{L})$ in plasma over the post-prandial period. Values are means \pm SEM. For statistical description, see "Methods"

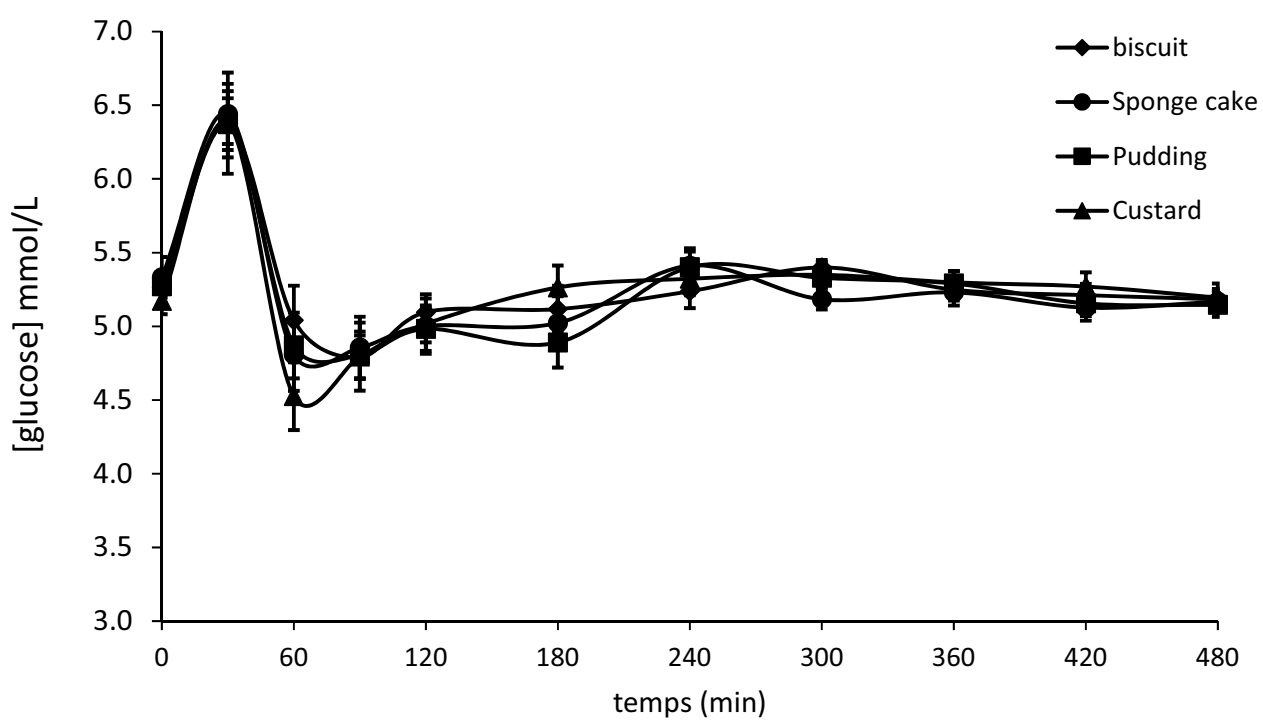

higher triglyceride plasma level compared to Biscuit with values higher for Custard at various time points (Time $\times$ Matrix effect $P<0.05$ at T90, T120 and T180, Fig. 8). This effect was confirmed after calculation of the AUC over the entire post-prandial period (AUC 480) (Fig. 8, Table 3, Matrix effect $P<0.05$ ).

\section{Discussion}

The aim of the present work was to determine to which extent food structure could have an impact on folate bioavailability (folates appearance in plasma) in humans in vivo. Bioavailability of folates depends on many factors 


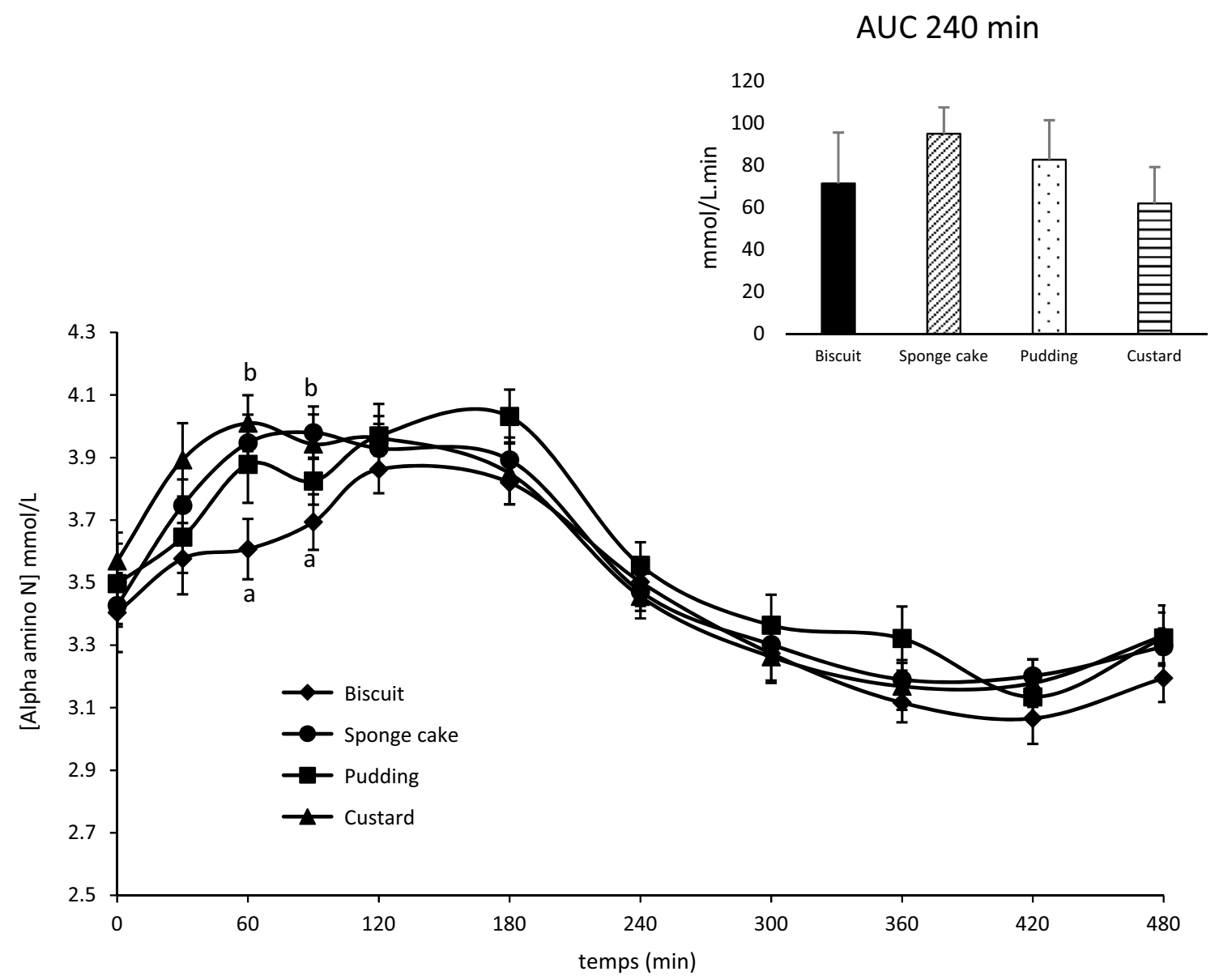

Fig. 7 Alpha amino nitrogen concentrations (mmol/L) in plasma over the post-prandial period and area under the curve (AUC, mmol/L.min) 240 min post-ingestion for the four tested matrices. Values are means \pm SEM. For statistical description, see "Methods"

as detailed above (food or host related) $[2,16]$. Among all the factors capable to influence bioavailability, one of them is less studied and often confused with others, namely the nature of the food matrix structure in which the micronutrients are incorporated.

\section{Assessment of folate bioavailability: our choice for a short-term study and validation of the study design}

As discussed in the literature [21-23], several methodologies exist to assess folate bioavailability: short-term kinetics and long-term studies. As the present work addresses the effect of food matrix on digestive process and ultimately folate bioavailability, a short-term protocol was more appropriate and the area under the plasma-response curve was used to assess folate bioavailability [6]. To obtain a significantly increased and measurable area under the curve, and because short-term studies are known to be relatively less sensitive, $1 \mathrm{mg}$ of folic acid per portion was included in the tested foods (i.e., the maximum daily intake in Europe, see "Introduction").
This one shot ingestion of $1 \mathrm{mg}$ folic acid by the volunteers (four repetitions over the experiment) did not have an impact on their basal fasted folate level in plasma over time (no period effect and a stable average of $3.55 \pm 0.17 \mathrm{ng} / \mathrm{mL}$ in folate plasma concentrations in the fasted state). The postprandial sampling covered the $8 \mathrm{~h}$ post-food ingestion to make sure not to miss the absorption peak [6].

\section{First demonstration of the matrix structure effect on folate bioavailability}

Using this methodology, Pudding and to a lesser extent Sponge cake matrices resulted in the biggest increase in plasma levels of total folates. From the analysis of the area under the curve, we have shown that the differences between the extreme AUC (Custard vs. Pudding) reached 39\% for AUC180 $(P<0.05)$ and $25 \%$ for AUC480 $(A<0.05)$ (when corrected from folate ingestion). These differences are far from being marginal and show that the food matrix structure is an important factor that could ultimately affect overall bioavailability of folates, particularly within the first hours 


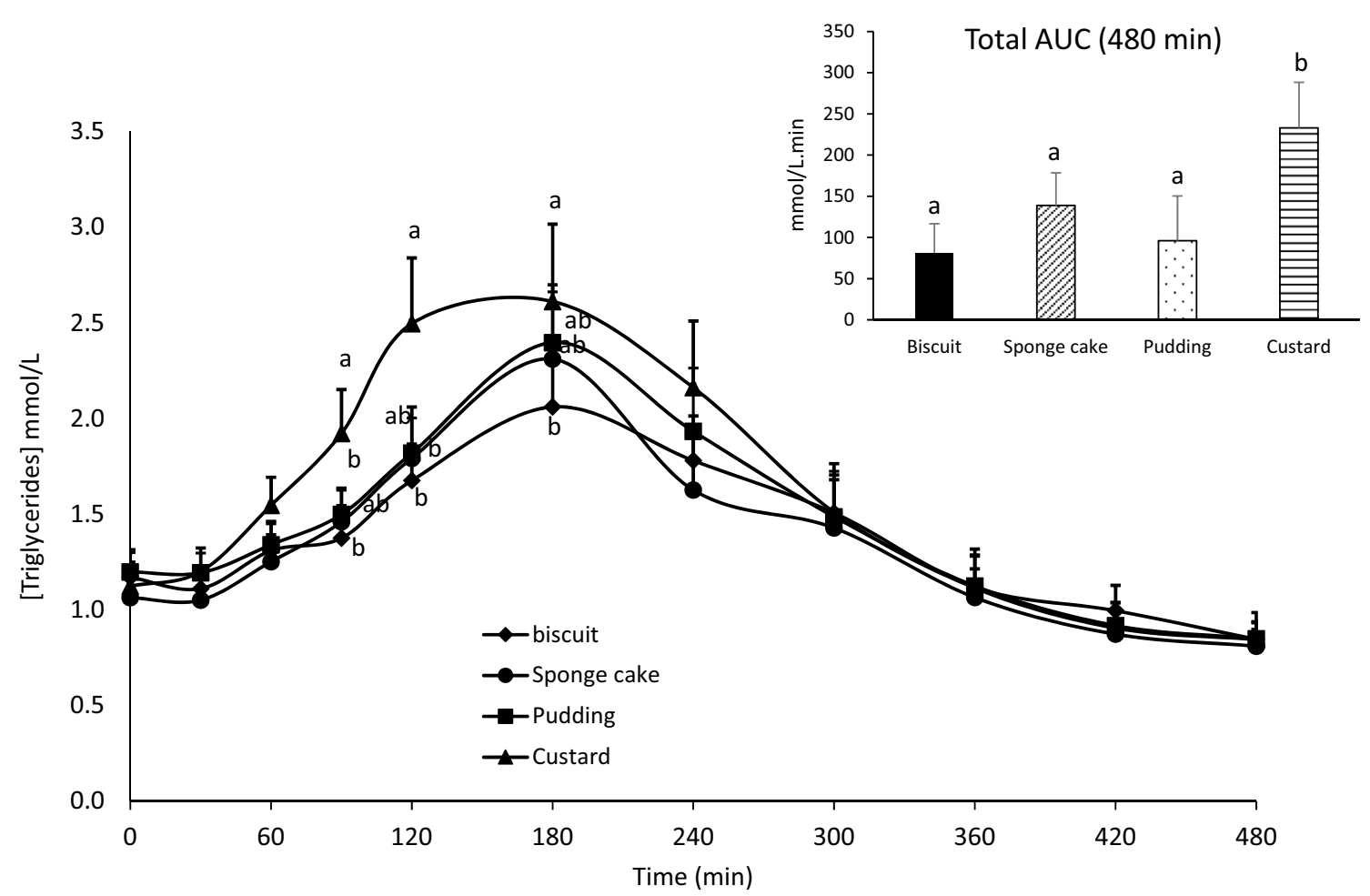

Fig. 8 Triglyceride concentrations $(\mathrm{mmol} / \mathrm{L}$ ) in plasma over the post-prandial period and area under the curve (AUC, mmol/L.min) over the entire (480 min) post-prandial period for the four tested matrices. Values are means \pm SEM. For statistical description, see "Methods"

post-matrix ingestion. To our knowledge, these results demonstrate for the first time that folate bioavailability can be significantly impacted by matrix structure alone, without potential confounding factors such as macronutrient composition and nature of folates since these confounding factors were here controlled and similar between matrices. Data exist in the literature, using the same AUC methodology, but comparisons were made using different quantities of the same food ingested [6], matrices were different in macronutrient composition [5], or the nature of folates supplied (natural folates partially polyglutamates vs. folic acid) were not similar [24]. Consequently, the differences observed in

Table 3 Plasma Triglycerides area under the curve (AUC, mmol/L. min) and maximum value over the post prandial period

\begin{tabular}{lcl}
\hline & AUC $480 \mathrm{~min}$ & Maximum value \\
\hline Biscuit & $81,1 \pm 35.6 \mathrm{a}$ & $2.07 \pm 0.21 \mathrm{a}$ \\
Sponge cake & $139.0 \pm 396 \mathrm{a}$ & $2.31 \pm 0.36 \mathrm{ab}$ \\
Pudding & $96,0 \pm 543 \mathrm{a}$ & $2.29 \pm 0.25 \mathrm{a}$ \\
Custard & $233.1 \pm 553 \mathrm{~b}$ & $2.70 \pm 0.34 \mathrm{~b}$ \\
\hline
\end{tabular}

Triglycerides AUC (mmol/L.min) 480 min post-ingestion of one of the four tested matrices: Biscuit, Sponge cake, Pudding and Custard. For each matrix, average maximum values (mmol) when the maximum value was observed. Values are means \pm SEM. For statistical description, see "Methods" these previous studies could result from the combined causes and not matrix structure only.

\section{Explanations for the observed variations in folate bioavailability}

The choice of nature of folate (i.e., folic acid) enrichment matrices in the present study was driven by two main reasons. The first one is that folic acid is known to be more resistant to heat treatments that were applied to some of the foods we tested during their processing. It could be seen from our data that no statistical difference in total folate content was observed between tested foods. However, the lowest numerical folate values were obtained for foods that were the driest and that underwent oven heating at $180{ }^{\circ} \mathrm{C}$ for $20 \mathrm{~min}$ or more (Fig. 1), suggesting a marginal impact of processing on folate content, even if not significant. On the contrary, humid (Pudding, Custard) and less heated (Custard) presented the highest folate contents. The second reason is that folic acid is a monoglutamate that can be directly absorbed by brush border cells whereas polyglutamates (high fraction of natural folates) need to be first hydrolysed into monoglutamates before any absorption. The utilization of folic acid could then overcome the "host effect" associated with a potential variability between individuals to hydrolyse polyglutamates, and enabled to focus on "matrix effect" we 
wanted to selectively separate. At this point, it is important to mention that the four foods tested contained flours (wheat and pea) and egg, which naturally contain folates (not necessarily folic acid) which could, therefore, present different kinetics of absorption and lower bioavailability compared to the supplemented folic acid [23]. Yet, it is now clearly stated by experts in the field of folate dietary recommendations that natural food folate bioavailability is incomplete relative to synthetic folic acid [25]. Moreover, the naturally present folates in the tested foods represented about $3 \%$ of the overall supply of folates, and then cannot account for the differences of bioavailability observed between matrices and discussed below.

Given the above, the analysis of the interactions between folates (and in our particular case folic acid) and matrix structure could explain why folate bioavailability was higher after Sponge cake and Pudding ingestion compared Custard and to a lesser extent Biscuit ingestion. Direct interactions between food components and folates have been already assumed but rarely studied [18]. The measurement of urinary excretion ratios of labelled folic acid relative to the quantity ingested in humans showed a tendency for a higher ratio when folic acid is supplemented alone than when consumed after a light breakfast [26]. Similarly, folate fortified skimmed milks presented a faster absorption than fortified whole milk [5]. These data suggest interactions between folates and the rest of the meal or components of the meal that could limit its overall absorption. At the molecular level, interaction of folates with folate-binding proteins (FBP) present in milk, for instance, have been shown to limit folate bioaccessibility in an in vitro model of gut [27, 28]. In the case of Biscuit and Custard matrices from the present study, an overall lower AUC is observed in the post-prandial state.

In the case of Biscuit, the folate plasma peak was delayed (Tmax delayed). These combined data suggest a longer digestion time and folate release/uptake within the gut lumen. This might be due to several and maybe combined factors, including (1) a swallowing of a less destructured bolus, (2) a delayed gastric emptying, and (3) a lower accessibility of macronutrients to digestive enzymes in the matrix [29]. On the contrary, differences in food bolus formation during mastication may have had an impact on the release of folates within the liquid fraction of the bolus, may occur as well as different gastric emptying rates. Both components are known to be highly dependent on micro-/macrostructure of the food as well as physical and chemical structures of food [30, 31]. These assumptions are consistent with the lower folate plasma concentrations and plasma folate profiles observed after Biscuit ingestion, as well as the low alpha-amino $\mathrm{N}$ and triglyceride plasma concentrations and profiles observed within the first $3 \mathrm{~h}$ following Biscuit ingestion. Indeed, this suggests that Biscuit ingestion led to a slower digestion process resulting in a delayed appearance in the plasma of various nutrients/ metabolites from the diet. This is in line with the continuous protein phase shown in Biscuit that may be less easily disrupted during the digestive process compared to Sponge cake and Pudding and may have entrapped the folates for a longer period of time over the digestive process, leading to a delayed bioavailability.

In the case of Custard, the story may be different since it is clear that the lipid and protein distribution within the matrix was different from the other matrices with globular lipids and protein aggregates (Fig. 3). This particular structure, and its liquid physical form, may have allowed the Custard to reach the duodenum rapidly, without any additional need for matrix disruption/degradation within the stomach. Even if we had no access to the digestive process in vivo, the macronutrient degradation through the digestive process can be hypothesized by the analysis of water- or lipid-soluble metabolite concentrations determined in plasma in the fed state. By inducing a large and significantly higher insulin peak as well as an increased triglyceride AUC compared to the other matrices (and alpha amino $\mathrm{N}$ plasma concentrations compared to biscuit), it is highly probable that gastric retention time for Custard was very low. Consequently, the nutrients rapidly appeared within the duodenum and jejunum that are the sites of absorption of lipids, glucose and amino acids. Then it can be hypothesized that folates, such as other nutrients, appeared very rapidly and in large quantities in the duodenum after Custard ingestion. Two hypotheses could then explain the lower absorption of folates: The capacities for folates entry into the cells could have been overflown, leading to a loss of folates within the faeces. Indeed, folates are absorbed via two systems: a specific saturable transport system (reduced folate carrier, RFC) when folate concentrations are low $(<10 \mu \mathrm{mol} / \mathrm{L})$, and a passive diffusion at higher concentrations [32, 33]. In our case, this hypothesis is probably not valid because folate absorption may occur mainly via a passive diffusion mechanism, suggesting that absorption process may not be the limiting factor. The other hypothesis would be an interaction of folates with highly available macronutrients (lipids and to a lesser extent proteins/ amino acids) that are present in the matrix. Data from Achon et al. [5] have shown that skimmed folate fortified milk was maximizing and accelerating folate absorption compared to whole fortified (differing only from skimmed fortified milk by lipid content) or non-fortified milk. Consequently, the structure of lipids in custard (globular), such as in whole milk, may limit folate absorption by a mechanism that should require further investigation.

\section{Conclusion}

The present study highlights that folate bioavailability and probably bioaccessibility can be altered by food matrix alone. Especially, the highest folate bioavailability was 
observed for Pudding and to a lesser extent Sponge cake whereas the lowest was for the two matrices presenting extreme rheological properties: Custard (liquid) and Biscuit (hard solid). The analysis of plasma kinetics of other nutrients/metabolites suggests that the lower bioavailability of folates when incorporated in Custard and Biscuit probably results from different origins. This could be a least overall efficient bioaccessibility of all nutrients in the gut lumen for Biscuit whereas a possible specific interaction of folates with matrix components (and possibly lipids) could occur in rapidly digested Custard. The validation of these hypotheses could be done by in vivo (in appropriate animal models) or in vitro studies via a fine analysis of kinetics of food disintegration along the gut. From mechanical disintegration of food bolus in the mouth [34], to chemical and enzymatic disintegration of the bolus within the stomach and the duodenum/ileum $[30,35]$ including interaction between folates and lipids (and maybe proteins) present in custard/milk in particular, many strands remain under research about the major food parameters that determine food behaviour during digestion and the related nutritional consequences.

Acknowledgements The authors thank J David and M Jarzaguet for technical assistance as well as the staff from UEN (F Laporte, A Caille, N Lyon-Belgy, V Pidou, D Dumas and H Parrot) for assistance during human experiments

Funding This work was financially supported by Carnot Qualiment, France.

\section{Compliance with ethical standards}

Conflict of interest Authors declare no conflict of interest.

\section{References}

1. Bailey LB, Gregory JF 3rd (1999) Folate metabolism and requirements. J Nutr 129(4):779-782. https://doi.org/10.1093/ jn/129.4.779

2. Naderi N, House JD (2018) Recent developments in folate nutrition. Adv Food Nutr Res 83:195-213. https://doi.org/10.1016/ bs.afnr.2017.12.006

3. Ramos MI, Allen LH, Mungas DM, Jagust WJ, Haan MN, Green R, Miller JW (2005) Low folate status is associated with impaired cognitive function and dementia in the Sacramento area Latino study on aging. Am J Clin Nutr 82(6):1346-1352. https://doi. org/10.1093/ajcn/82.6.1346

4. EFSA (2014) Scientific opinion on Dietary Reference Values for folate. EFSA J 12(11):3893

5. Achon M, Arrate A, Alonso-Aperte E, Varela-Moreiras G (2011) Plasma folate concentrations after a single dose ingestion of whole and skimmed folic acid fortified milks in healthy subjects. Eur $\mathbf{J}$ Nutr 50(2):119-125. https://doi.org/10.1007/s00394-010-0121-Z

6. Prinz-Langenohl R, Bronstrup A, Thorand B, Hages M, Pietrzik K (1999) Availability of food folate in humans. J Nutr 129(4):913916. https://doi.org/10.1093/jn/129.4.913
7. Crider KS, Devine O, Qi YP, Yeung LF, Sekkarie A, Zaganjor I, Wong E, Rose CE, Berry RJ (2019) Systematic review and Bayesian meta-analysis of the dose-response relationship between folic acid intake and changes in blood folate concentrations. Nutrients. https://doi.org/10.3390/nu11010071

8. Atta CA, Fiest KM, Frolkis AD, Jette N, Pringsheim T, St Germaine-Smith C, Rajapakse T, Kaplan GG, Metcalfe A (2016) Global birth prevalence of spina bifida by folic acid fortification status: a systematic review and meta-analysis. Am J Public Health 106(1):e24-34. https://doi.org/10.2105/ajph.2015.30290 2

9. Dwyer JT, Wiemer KL, Dary O, Keen CL, King JC, Miller KB, Philbert MA, Tarasuk V, Taylor CL, Gaine PC, Jarvis AB, Bailey RL (2015) Fortification and health: challenges and opportunities. Adv Nutr 6(1):124-131. https://doi.org/10.3945/an.114.007443

10. Patel KR, Sobczynska-Malefora A (2017) The adverse effects of an excessive folic acid intake. Eur J Clin Nutr 71(2):159-163. https://doi.org/10.1038/ejen.2016.194

11. Reynolds EH (2016) What is the safe upper intake level of folic acid for the nervous system? Implications for folic acid fortification policies. Eur J Clin Nutr 70(5):537-540. https://doi. org/10.1038/ejen.2015.231

12. Swedish Council on Health Technology A (2007) SBU systematic review summaries. In: benefits and risks of fortifying flour with folic acid to reduce the risk of neural tube defects: a systematic review. Swedish Council on Health Technology Assesment (SBU) Copyright (c) 2007 by the Swedish council on health technology assessment, Stockholm

13. Hughes CF, Ward M, Hoey L, McNulty H (2013) Vitamin B12 and ageing: current issues and interaction with folate. Ann Clin Biochem 50(Pt 4):315-329. https://doi.org/10.1177/0004563212 473279

14. Zhang SL, Chen TS, Ma CY, Meng YB, Zhang YF, Chen YW, Zhou YH (2016) Effect of vitamin B supplementation on cancer incidence, death due to cancer, and total mortality: a PRISMAcompliant cumulative meta-analysis of randomized controlled trials. Medicine 95(31):e3485. https://doi.org/10.1097/md.00000 00000003485

15. Dolin CD, Deierlein AL, Evans MI (2018) Folic acid supplementation to prevent recurrent neural tube defects: 4 milligrams is too much. Fetal Diagn Ther 44(3):161-165. https://doi. org/10.1159/000491786

16. Brouwer IA, van Dusseldorp M, West CE, Steegers-Theunissen RP (2001) Bioavailability and bioefficacy of folate and folic acid in man. Nutr Res Rev 14(2):267-294. https://doi.org/10.1079/ nrr200126

17. McKillop DJ, McNulty H, Scott JM, McPartlin JM, Strain JJ, Bradbury I, Girvan J, Hoey L, McCreedy R, Alexander J, Patterson BK, Hannon-Fletcher M, Pentieva K (2006) The rate of intestinal absorption of natural food folates is not related to the extent of folate conjugation. Am J Clin Nutr 84(1):167-173. https ://doi.org/10.1093/ajen/84.1.167

18. Ohrvik VE, Witthoft CM (2011) Human folate bioavailability. Nutrients 3(4):475-490. https://doi.org/10.3390/nu3040475

19. Chacornac JP, Barnouin J, Houlier ML (1993) Automated microdetermination by transfer analyzer of circulating alpha-amino nitrogen. Reprod Nutr Dev 33(2):99-108

20. Ruggeri S, Vahteristo LT, Aguzzi A, Finglas P, Carnovale E (1999) Determination of folate vitamers in food and in Italian reference diet by high-performance liquid chromatography. J Chromatogr A 855(1):237-245

21. McNulty H, Pentieva K (2004) Folate bioavailability. Proc Nutr Soc 63(4):529-536

22. Finglas PM, Witthoft CM, Vahteristo L, Wright AJ, Southon S, Mellon FA, Ridge B, Maunder P (2002) Use of an oral/intravenous dual-label stable-isotope protocol to determine folic acid 
bioavailability from fortified cereal grain foods in women. J Nutr 132(5):936-939

23. Gregory JF 3rd (1382s) Case study: folate bioavailability. J Nutr 131(4 Suppl):1376s-1382s. https://doi.org/10.1093/ jn/131.4.1376S

24. Carter B, Monsivais P, Drewnowski A (2010) Absorption of folic acid and ascorbic acid from nutrient comparable beverages. J Food Sci 75(9):H289-293. https://doi.org/10.111 $1 / \mathrm{j} .1750-3841.2010 .01844 . x$

25. McNulty H, Scott JM (2008) Intake and status of folate and related B-vitamins: considerations and challenges in achieving optimal status. Br J Nutr 99(Suppl 3):S48-54. https://doi.org/10.1017/ s0007114508006855

26. Pfeiffer CM, Rogers LM, Bailey LB, Gregory JF 3rd (1997) Absorption of folate from fortified cereal-grain products and of supplemental folate consumed with or without food determined by using a dual-label stable-isotope protocol. Am J Clin Nutr 66(6):1388-1397. https://doi.org/10.1093/ajcn/66.6.1388

27. Arkbage K, Verwei M, Havenaar R, Witthoft C (2003) Bioaccessibility of folic acid and (6S)-5-methyltetrahydrofolate decreases after the addition of folate-binding protein to yogurt as studied in a dynamic in vitro gastrointestinal model. J Nutr 133(11):36783683. https://doi.org/10.1093/jn/133.11.3678

28. Verwei M, Arkbage K, Mocking H, Havenaar R, Groten J (2004) The binding of folic acid and 5-methyltetrahydrofolate to folatebinding proteins during gastric passage differs in a dynamic in vitro gastrointestinal model. J Nutr 134(1):31-37. https://doi. org/10.1093/jn/134.1.31
29. Sensoy I (2014) A review on the relationship between food structure, processing, and bioavailability. Crit Rev Food Sci Nutr 54(7):902-909. https://doi.org/10.1080/10408398.2011.619016

30. Lentle RG, Janssen PW (2010) Manipulating digestion with foods designed to change the physical characteristics of digesta. Crit Rev Food Sci Nutr 50(2):130-145. https://doi.org/10.1080/10408 390802248726

31. McClements DJ, Decker EA, Park Y (2009) Controlling lipid bioavailability through physicochemical and structural approaches. Crit Rev Food Sci Nutr 49(1):48-67. https://doi. org/10.1080/10408390701764245

32. Luka Z (2008) Methyltetrahydrofolate in folate-binding protein glycine N-methyltransferase. Vitam Horm 79:325-345. https:// doi.org/10.1016/s0083-6729(08)00411-1

33. Selhub J, Powell GM, Rosenberg IH (1984) Intestinal transport of 5-methyltetrahydrofolate. Am J Physiol 246(5 Pt 1):G515-520. https://doi.org/10.1152/ajpgi.1984.246.5.G515

34. Bonnet G, Batisse C, Peyron MA, Nicolas E, Hennequin M (2018) Which variables should be controlled when measuring the granulometry of a chewed bolus? A systematic review. J Texture Stud. https://doi.org/10.1111/jtxs.12376

35. Nau F, Nyemb-Diop K, Lechevalier V, Floury J, Serriere C, Stroebinger N, Boucher T, Guerin-Dubiard C, Ferrua MJ, Dupont D, Rutherfurd SM (2019) Spatial-temporal changes in pH, structure and rheology of the gastric chyme in pigs as influenced by egg white gel properties. Food Chem 280:210-220. https://doi. org/10.1016/j.foodchem.2018.12.042 